\title{
Chromogranin A predicts outcome in prostate cancer patients treated with abiraterone
}

\author{
Salvatore Luca Burgio ${ }^{1, *}$, Vincenza Conteduca ${ }^{1, *}$, Cecilia Menna', Elisa Carretta ${ }^{2}$, \\ Lorena Rossi', Emanuela Bianchi', Barbara Kopf', Francesca Fabbri' ${ }^{2}$, Dino Amadori ${ }^{1}$ \\ and Ugo De Giorgi ${ }^{1}$ \\ ${ }^{1}$ Medical Oncology and ${ }^{2}$ Biostatistics and Clinical Trials, Istituto Scientifico Romagnolo per lo Studio e la Cura dei \\ Tumori (I.R.S.T.) - IRCCS, Via Maroncelli 40, 47014 Meldola (FC), Italy \\ *(S L Burgio and V Conteduca contributed equally to this work)
}

Correspondence should be addressed to U De Giorgi

Email

ugo.degiorgi@irst.emr.it

\begin{abstract}
In this retrospective study, we evaluated the chromogranin A ( $\mathrm{CgA}$ ) baseline value as a predictor of clinical outcome in patients with metastatic castration-resistant prostate cancer (CRPC) treated with abiraterone $1000 \mathrm{mg}$ per day, whose disease progressed after docetaxel chemotherapy. In the 48 evaluable patients, serum CgA level was normal when $<120 \mathrm{ng} / \mathrm{ml}$ (group $\mathrm{A}, n=16$ ), within three times the upper normal value (UNV) when between 120 and 360 (group $B, n=16$ ), more than three times the UNV when $\geq 360 \mathrm{ng} / \mathrm{ml}$ (group $C, n=16$ ). Decline in PSA level $\geq 50 \%$ or more (PSA RR) was observed in 26 of 48 (54\%) patients. PSA response rate did not correlate with the $\mathrm{CgA}$ groups. $\mathrm{CgA}$ levels more than three times the UNV predicted an early radiological progressive disease in eight of 11 cases $(73 \%)$. The median progression-free survival (PFS) among the CgA groups $A, B$, and $C$ was 9.2, 9.2, and 4.8 months respectively, $P=0.0459$. The median overall survival (OS) among the CgA groups was $19.0,18.8$, and 10.8 months respectively, $P=0.2092$. In the multivariate analysis, PSA RR (nonresponsive vs responsive) and CgA levels (group 3 vs groups $1+2$ ) were predictors of PFS ( $P=0.0002$ and $P=0.0047$ respectively), whereas PSA RR only was significantly associated with OS $(P=0.0024)$, while CgA levels remained of borderline significance $(P=0.0919)$. A serum CGA level more than three times the UNV predicted PFS and showed a trend vs OS prediction, independently from PSA response, in CRPC patients treated with abiraterone.
\end{abstract}
Key Words
- chromogranin A
- CgA
- castration-resistant prostate cancer
- CRPC
- abiraterone
- PSA
- bone flare

\section{Introduction}

Metastatic castration-resistant prostate cancer (CRPC) is a leading cause of cancer-related mortality worldwide (Siegel et al. 2013). Unfortunately, despite advances in treatment, the prognosis remains poor (Petrylak et al. 2004, Tannock et al. 2004, de Bono et al. 2010). Abiraterone acetate is a selective inhibitor of androgen biosynthesis that potently and irreversibly blocks cytochrome P-450c17 (CYP17), resulting in virtually undetectable serum and intratumoral androgens (Attard et al. 2009). Treatment with abiraterone improved survival of patients with metastatic CRPC who had already received docetaxel therapy and showed a trend toward improved overall survival (OS) of those who had not received previous chemotherapy (Fizazi et al. 2012, Ryan et al. 2013). A major limitation on abiraterone management is the lack of validated biomarkers of response to

Published by Bioscientifica Ltd 
therapy and the potential effect of PSA modulation that could impair its role as an indicator of response to therapy (de Bono et al. 2011, Burgio et al. 2014).

Chromogranin A (CgA) is an acidic glycoprotein that is commonly expressed by neuroendocrine cells and constitutes one of the most profuse components of secretory granules. CgA appears to be the most sensitive marker and is most frequently used for detecting neuroendocrine differentiation either at the tissue level or in the general circulation. The availability of such a specific circulating marker for the neuroendocrine component could allow us to easily detect and monitor neuroendocrine differentiation in prostate cancer patients (Berruti et al. 2005, Sciarra et al. 2009, Matei et al. 2012).

In this retrospective study, we evaluated baseline serum CgA levels as a predictor of clinical outcome in patients with metastatic CRPC treated with abiraterone.

\section{Subjects and methods}

\section{Patients}

This retrospective study included 55 consecutive metastatic CRPC patients progressing after docetaxel chemotherapy treated abiraterone and who had serum PSA and CgA levels performed at baseline. Seven patients were excluded from the analysis due to renal insufficiency and/or concomitant treatment with proton pump inhibitors that could influence serum CgA levels (Taplin et al. 2005). In the 48 evaluable patients, serum CgA level was considered normal, as reported by the kit for CgA, when $<120 \mathrm{ng} / \mathrm{ml}$ (group A, $n=16$ ), within three times the upper normal value (UNV) when between 120 and 360 (group B, $n=16$ ), more than three times the UNV when $\geq 360 \mathrm{ng} / \mathrm{ml}$ (group C, $n=16$ ). Eligibility criteria for the use of abiraterone in CRPC required histological confirmation of adenocarcinoma of the prostate without neuroendocrine differentiation or small cell histology progressing on androgen deprivation. Patients received at least one chemotherapeutic regimen with docetaxel, but not more than two cytotoxic chemotherapy regimens for metastatic CRPC. Prior ketoconazole therapy was not permitted. Additional eligibility criteria included an Eastern Cooperative Oncology Group (ECOG) performance status $0-2$; adequate cardiac, renal, hepatic, and bone marrow function; normal serum potassium level; and ongoing androgen deprivation therapy with serum testosterone $<50 \mathrm{ng} / \mathrm{dl}$. The retrospective study was approved by the Institutional Review Board.

\section{Treatment and evaluation}

Therapy consisted of abiraterone acetate $1000 \mathrm{mg}$ daily associated with prednisone $5 \mathrm{mg}$ twice daily in a 28-day cycle. Treatment was given continuously until there was an evidence of either progressive disease (PD) or unacceptable toxicity. Before starting abiraterone treatment, patients underwent baseline blood sampling for PSA and $\mathrm{CgA}$. Plasma CgA levels (in $\mu \mathrm{g}$ per liter) were measured in duplicate using a two-side 'sandwich' technique with two selected antibodies that bind to different epitopes of human chromogranin A (Epitope Diagnostics, Inc. - EDI Human Chromogranin A ELISA Kit, San Diego, CA, USA), following the manufacturer's instructions. The sensitivity is $2 \mu \mathrm{g} / \mathrm{l}$. The inter-assay coefficients of variation of $\mathrm{CgA}$ assay were 7.3 and $3.1 \%$ respectively. The normal range reported by the kit for $\mathrm{CgA}$ was $0-120 \mathrm{ng} / \mathrm{ml}$. Patients were evaluated monthly for serological PSA response and safety. A CT scan was performed every 3 months of abiraterone. Disease progression was defined according to PCWG2 criteria (Scher et al. 2008). Adverse events were graded using the National Cancer Institute Common Terminology Criteria for Adverse Events (CTCAE), version 3.

\section{Statistical analysis}

A receiver-operating characteristic (ROC) curves were used to evaluate the diagnostic role of baseline serum $\mathrm{CgA}$ for determining the response to no response to treatment with abiraterone. The area under the ROC curve (AUC) was calculated.

Data were summarized by frequency for categorical variables and by median and range for continuous variables. Continuous variables were compared using the Wilcoxon test. Association between categorical variables was assessed using the Fisher's exact test, when appropriate. Differences were considered statistically significant when $P<0.05$. The cutoffs for $\mathrm{CgA}$ in response to abiraterone were calculated through the AUC. Progression-free survival (PFS) was defined as the time elapsed between the date of the start of abiraterone and the date of PD or death or, if neither PD nor death occurred, the date of the last follow-up visit. OS was defined as the elapsed time between the start of abiraterone and the date of either death or the last follow-up in living patients at the time of analysis. Kaplan-Meier survival plots were generated on the basis of $\mathrm{CgA}$ groups and the curves were compared using log-rank test. A Cox-regression model was carried out with a univariable and multivariate approach. The following variables were included in the univariate

Published by Bioscientifica Ltd. 
analysis: Gleason score (8-10 vs $\leq 7)$, Eastern Cooperative Oncology Group (ECOG) performance status (PS; $\geq 2$ vs $0-1$ ), line of therapy ( $\geq 3$ vs 2), PSA response rate (PSA RR; $<50$ vs $>50 \%$ ), and serum CgA level (group $C$ vs groups $\mathrm{A}+\mathrm{B})$. Variables not fitting at univariate analysis were excluded for the multivariate model. Significance level from the univariate analysis for inclusion in the multivariate final model was more liberally set at a 0.1 level, according to Fagerland et al. (2008) and Fagerland \& Hosmer (2013). All other significance levels were set at a $P$ value of $<0.05$.

\section{Results}

\section{Patients' characteristics}

Between March 2011 and August 2012, 48 CRPC patients were considered evaluable for this study, with serum PSA and $\mathrm{CgA}$ levels measurement at baseline before starting abiraterone. The median serum CgA level was $235.5 \mathrm{ng} / \mathrm{ml}$. Of the 48 evaluable patients, serum CgA level was considered normal in 16, 33\% (CgA group A), elevated but within three times the UNV in 16, 33\% (CgA group $\mathrm{B}$ ), and elevated more than three times the UNV in $16,33 \%$ (CgA group C). Characteristics of the 48 evaluable patients included in the study are summarized in Table 1.

\section{Relationship between baseline $\mathrm{CgA}$ levels and response}

The three patients with baseline liver metastases had increased levels of $\mathrm{CgA}$ (one case in $\mathrm{CgA}$ group B and two in $\mathrm{CgA}$ group $\mathrm{C}$ ), while the six cases with lung metastases were distributed across the three $\mathrm{CgA}$ groups (two in $\mathrm{CgA}$ group $\mathrm{A}$, three in $\mathrm{CgA}$ group $\mathrm{B}$, and one in $\mathrm{CgA}$ group $\mathrm{C}$ ). The CT response was assessed every 3 months of follow-up in 45 of 48 patients, while three cases experienced early clinical deterioration and did not perform the follow-up CT scan. Three month CT results were as follows: complete response $(n=1,2 \%)$, partial response $(n=7,15.5 \%)$, stable disease $(n=25,55.5 \%)$, PD $(n=11,25 \%)$, and not evaluable $(n=1,2 \%)$. Therapy was interrupted in one case due to pulmonary thromboembolism and one due to not abiraterone-related infective diarrhea. The early PD at 3-month CT-scan occurred in one of 16 patients (7\%) in CgA group A, two of 16 (13\%) in CgA group B, and eight of 16 (50\%) in CgA group C. Within the CgA group C, five of seven $(71 \%)$ patients with CgA levels more than five times the UNV had early PD.

The three cases with early PD in CgA groups A and B had baseline bone lesions and experienced bone progression only, whereas of eight cases with early PD in the CgA group C, six had bone progression (five with baseline bone lesions), four liver progression (only one with baseline

Table 1 Clinical characteristics of patients at baseline

\begin{tabular}{|c|c|c|c|c|c|}
\hline Characteristic & Overall n (\%) & $\begin{array}{c}\text { CgA }<120 \\
\text { group } A n(\%)\end{array}$ & $\begin{array}{l}\text { CgA } \geq 120<360 \\
\text { group B } n(\%)\end{array}$ & $\begin{array}{c}\text { CgA } \geq \mathbf{3 6 0} \\
\text { group } C n(\%)\end{array}$ & $\boldsymbol{P}$ \\
\hline All patients & 48 & $16(33 \%)$ & $16(33 \%)$ & $16(33 \%)$ & \\
\hline Median age (range) (years) & $73(57-90)$ & $72(57-86)$ & $75(63-87)$ & $73(61-90)$ & 0.5609 \\
\hline \multicolumn{6}{|l|}{ ECOG performance status } \\
\hline $0-1$ & $45(94 \%)$ & $16(100 \%)$ & $14(87.5 \%)$ & $15(94 \%)$ & 0.4076 \\
\hline 2 & $3(6 \%)$ & 0 & $2(12.5 \%)$ & $1(6 \%)$ & \\
\hline \multicolumn{6}{|l|}{ Gleason score } \\
\hline $6-7$ & $20(42 \%)$ & $7(44 \%)$ & $7(44 \%)$ & $6(38 \%)$ & 0.9711 \\
\hline $8-9$ & $27(56 \%)$ & $9(56 \%)$ & $9(56 \%)$ & $9(56 \%)$ & \\
\hline Unknown & $1(2 \%)$ & 0 & 0 & $1(6 \%)$ & \\
\hline \multicolumn{6}{|l|}{ Bone metastasis } \\
\hline Absent & $10(21 \%)$ & $4(25 \%)$ & $3(19 \%)$ & $3(19 \%)$ & 1.0000 \\
\hline Present & $38(79 \%)$ & $12(75 \%)$ & $13(81 \%)$ & $13(81 \%)$ & \\
\hline \multicolumn{6}{|l|}{ Visceral metastasis } \\
\hline Absent & $39(81 \%)$ & $14(87.5 \%)$ & $12(75 \%)$ & $13(81 \%)$ & 0.8953 \\
\hline Present & $9(19 \%)$ & $2(12.5 \%)$ & $4(25 \%)$ & $3(19 \%)$ & \\
\hline \multicolumn{6}{|l|}{$\begin{array}{l}\text { No. of previous } \\
\text { chemotherapeutic regimens }\end{array}$} \\
\hline One & $21(44 \%)$ & $8(50 \%)$ & $9(56 \%)$ & $4(25 \%)$ & 0.1690 \\
\hline Two or more & $27(56 \%)$ & $8(50 \%)$ & $7(44 \%)$ & $12(75 \%)$ & \\
\hline \multicolumn{6}{|l|}{ Baseline PSA } \\
\hline Median (range) (ng/ml) & $32.5(1-1501)$ & $17.3(1.5-1501)$ & $35.0(1-1435)$ & $35.4(5-1083)$ & 0.9172 \\
\hline \multicolumn{6}{|l|}{ Baseline CgA } \\
\hline Median (range) (ng/ml) & $235.5(22-1000)$ & $83(22-118)$ & $235.5(125-344)$ & $579(382-1000)$ & $<0.0001$ \\
\hline
\end{tabular}

CgA, chromogranin A; ECOG, Eastern Cooperative Oncology Group.

http://erc.endocrinology-journals.org DOI: 10.1530/ERC-14-0071 (c) 2014 Society for Endocrinology Printed in Great Britain
Published by Bioscientifica Ltd 


\section{Discussion}

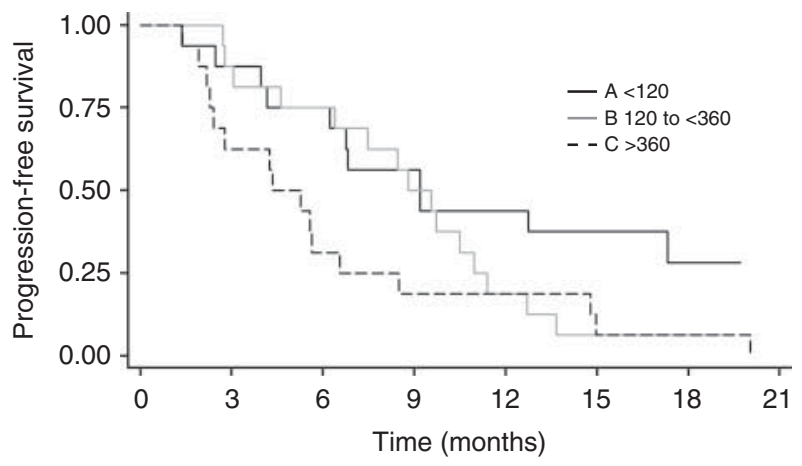

Figure 1

Kaplan-Meier plots illustrating progression-free survival (PFS) according to CgA groups.

liver lesions), two lung progression (one with baseline lung lesions), and one with nodal progression (baseline nodal disease only). The ROC curves of CT response (CR, PR, SD vs $\mathrm{PD})$ registered an area (AUC) of $0.81 \pm 0.07$.

All 48 patients were evaluable for PSA response. Decline in PSA level of 50\% or more was observed in 26 of 48 (54\%) patients. PSA decline $\geq 50 \%$ did not correlate with the CgA groups: ten PSA response occurred in CgA group A, eight in $\mathrm{CgA}$ group $\mathrm{B}$, and eight cases in $\mathrm{CgA}$ group $\mathrm{C}$. The AUC for the PSA response was $0.57 \pm 0.08$, suggesting that baseline serum $\mathrm{CgA}$ is a poor marker of the decline in PSA.

\section{Outcome prediction}

The median follow-up was 21.7 months (range, 1-28.5). In all 48 patients, the median PFS time from baseline was 7.1 months (95\% CI 5.3-9.5), while the median OS time from baseline was 17.6 months (95\% CI 11.8-21.9). At the time of analysis, six patients (12.5\%) were considered free of progression, whereas 30 (62.5\%) patients had died.

A statistical significant difference was reported in the median PFS among the CgA groups A, B, and C: 9.2 months (95\% CI 4.1-...) vs 9.2 months (95\% CI 4.6-10.9) vs 4.8 months (95\% CI 2.3-6.5) respectively, $P=0.0459$ (Fig. 1). A trend toward a decreased in the median OS was observed among the CgA groups: 19.0 months (95\% CI 9.6-...) vs 18.8 months (95\% CI $11.8-\ldots)$ vs 10.8 months (95\% CI 3.4-17.7), respectively, $P=0.2092$ (Fig. 2). In the multivariate analysis, PSA RR and CgA levels were predictors of PFS (HR=3.8, 95\% CI 1.9-7.6, $P=0.0002$ and $\mathrm{HR}=2.7,95 \%$ CI $1.3-5.2, P=0.0047$ respectively) (Table 2), while PSA RR only was significantly associated with OS $(\mathrm{HR}=3.2,95 \%$ CI 1.5-6.9, $P=0.0024)$, whereas $\mathrm{CgA}$ levels remained of borderline significance $(\mathrm{HR}=1.9$, 95\% CI 0.9-4.1, $P=0.0919$ ) (Table 3).
Serum CgA levels are elevated in $15-48 \%$ of patients with prostate cancer, depending on the clinical stage and grading (Deftos et al. 1996, Kimura et al. 1997, Berruti et al. 2000). Elevated serum CgA levels have correlated with the amount of CgA-positive prostate tumor cells and may reflect neuroendocrine differentiation of prostate cancer (Angelsen et al. 1997). Neuroendocrine cells in the prostate are not regulated by androgens and are resistant to hormonal therapies. In the high serum $\mathrm{CgA}$, which would have more neuroendocrine cells with less androgen receptors, so we postulated that patients with CRPC associated with high serum CgA levels may show resistance to treatment with abiraterone and a poor prognosis.

In the present study, we analyzed retrospectively 48 consecutive evaluable metastatic CRPC patients progressing after docetaxel chemotherapy treated abiraterone and who had both serum PSA and CgA levels performed at baseline. Our results showed that serum CgA levels elevated more than three times the UNV are able to predict PFS of CRPC patients treated with abiraterone and can contribute to predict early PD within 3 months in $50 \%$ of cases. To our knowledge, this is the first study that evaluated the role of $\mathrm{CgA}$ for outcome prediction in patients with CRPC treated with abiraterone.

$\mathrm{CgA}$ is recognized as a useful predictive marker in patients with prostatic cancer with lower PSA levels (Isshiki et al. 2002, Conteduca et al. 2014). However, in our experience, the lack of correlation between low PSA levels and high CgA values may be expression of a selection of patients with far advanced CRPC with a neuroendocrine differentiation in a context of a

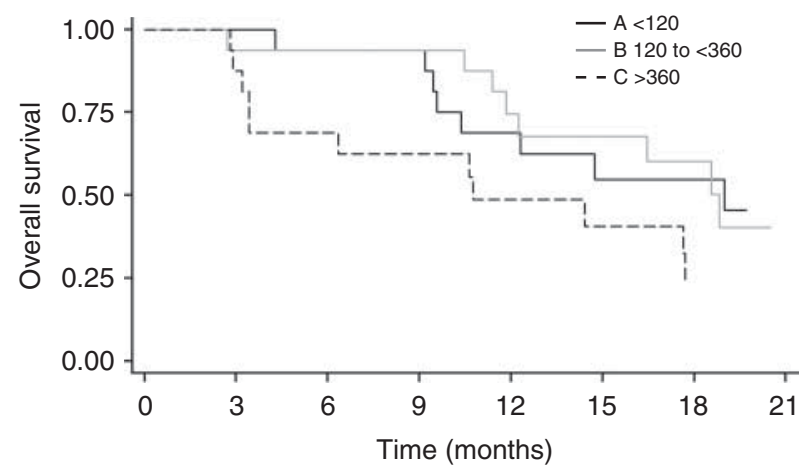

Figure 2

Kaplan-Meier plots illustrating overall survival (OS) according to CgA groups.

Published by Bioscientifica Ltd. 
Table 2 Univariate and multivariate Cox regression analyses for PFS in patients with castration-resistant prostate cancer treated with abiraterone

\begin{tabular}{|c|c|c|c|c|c|c|c|}
\hline \multirow[b]{2}{*}{ Parameters } & \multirow{2}{*}{$\begin{array}{l}\text { No. of } \\
\text { patients }\end{array}$} & \multicolumn{3}{|c|}{ Univariate analysis PFS risk from baseline } & \multicolumn{3}{|c|}{ Multivariate analysis PFS risk from baseline } \\
\hline & & $\mathrm{HR}$ & $95 \% \mathrm{Cl}$ & $P$ & $H R$ & $95 \% \mathrm{Cl}$ & $P$ \\
\hline Gleason score (8-9 vs 6-7) & 48 & 0.8 & $0.4-1.5$ & 0.4691 & & & \\
\hline $\begin{array}{l}\text { No. of previous chemotherapeutic } \\
\text { regimens ( } \geq 2 \text { vs } 1)\end{array}$ & 48 & 1.5 & $0.8-2.8$ & 0.2104 & & & \\
\hline ECOG performance status ( 2 vs $0-1$ ) & 48 & 0.8 & $0.2-2.5$ & 0.6743 & & & \\
\hline PSA decline $(<50$ vs $\geq 50 \%)$ & 48 & 3.1 & $1.6-5.9$ & 0.0007 & 3.8 & $1.9-7.6$ & 0.0002 \\
\hline $\begin{array}{l}\text { Baseline CgA levels (group } 3 \text { vs } \\
\text { groups } 1-2 \text { ) }\end{array}$ & 48 & 2.0 & $1.1-3.8$ & 0.0304 & 2.7 & $1.3-5.2$ & 0.0047 \\
\hline
\end{tabular}

PFS, progression-free survival; HR, hazard ratio; ECOG, Eastern Cooperative Oncology Group.

heterogeneous tumor volume including a rich component with PSA expression. In the multivariate analysis, PSA RR and CgA levels were able to predict PFS $(P=0.0002$ and $P=0.0047$ respectively), while PSA RR only was significantly associated with $\mathrm{OS}(P=0.0024)$, whereas $\mathrm{CgA}$ levels remained of borderline significance $(P=0.0919)$. Instead, PSA decline $\geq 50 \%$ did not correlate with the $\mathrm{CgA}$ groups. The AUC for the PSA response was 0.57, suggesting that baseline serum $\mathrm{CgA}$ level is a poor marker of the declines in PSA level of $50 \%$ or more. While the ROC curves of CT response registered an area of 0.81 that is in line with the capacity of high CgA levels to predict early PD within 3 months in 50\% of cases. Thus high CgA levels appeared to be the expression of tumor resistance to abiraterone. Elevated serum CgA levels usually correlate with the amount of neuroendocrine differentiation in prostate tumor (Angelsen et al. 1997). Emerging evidence suggests that the acquisition of epithelial-mesenchymal transition and cancer stem cell phenotype are associated with the development of neuroendocrine differentiation in CRPC, further contributing to resistance to hormonal therapies (Conteduca et al. 2014).
Despite a lack of correlation between baseline serum CgA levels with PSA response, the prediction of PFS could be related to the fact that serum CgA levels are an expression of a subclone of prostate cancer cells with neuroendocrine differentiation that could represent a minority of the tumor volume; this has an impact on overall clinical progression without affecting PSA response, which is related to the activity of abiraterone on the non-neuroendocrine component.

The small sample size and the retrospective nature of the analysis were the major limitations of our study. The interpretation of PFS is difficult in a retrospective study, even if there was a high compliance with the PSA and CT assessments. Moreover, we excluded cases with known factors that could influence serum CgA levels (renal insufficiency and/or concomitant proton pump inhibitors), but we cannot exclude that other concomitant medications, frequently used in an elderly patient population like that with CRPC, could have a smaller but significant impact on the CgA values (Taplin et al. 2005). The CgA group classification used in the present study was based on fairly arbitrary thresholds; nevertheless

Table 3 Univariate and multivariate Cox regression analyses for OS in patients with castration-resistant prostate cancer treated with abiraterone

\begin{tabular}{l} 
Parameters \\
\hline Gleason score (8-9 vs $6-7)$ \\
No. of previous chemotherapeutic \\
regimens ( $\geq 2$ vs 1 ) \\
ECOG performance status ( 2 vs $0-1$ ) \\
PSA decline ( $<50$ vs $\geq 50 \%$ ) \\
Baseline CgA levels (group 3 vs \\
groups $1-2$ )
\end{tabular}

\begin{tabular}{c}
\hline $\begin{array}{c}\text { No. of } \\
\text { patients }\end{array}$ \\
\hline 48 \\
48 \\
48 \\
48 \\
48
\end{tabular}

\begin{tabular}{|c|c|c|}
\hline \multicolumn{3}{|c|}{ Univariate analysis OS risk from baseline } \\
\hline$H R$ & $95 \% \mathrm{Cl}$ & $P$ \\
\hline 0.8 & $0.4-1.6$ & 0.4969 \\
\hline 1.8 & $0.8-3.9$ & 0.1597 \\
\hline 1.2 & $0.3-5.1$ & 0.8066 \\
\hline 3.3 & $1.5-7.0$ & 0.0023 \\
\hline 1.9 & $0.9-4.1$ & 0.0853 \\
\hline
\end{tabular}

\begin{tabular}{|c|c|c|}
\hline \multicolumn{3}{|c|}{ Multivariate analysis OS risk from baseline } \\
\hline $\mathrm{HR}$ & $95 \% \mathrm{Cl}$ & $P$ \\
\hline
\end{tabular}

OS, overall survival; HR, hazard ratio; ECOG, Eastern Cooperative Oncology Group.

http://erc.endocrinology-journals.org DOI: 10.1530/ERC-14-0071 (c) 2014 Society for Endocrinology Printed in Great Britain
Published by Bioscientifica Ltd.

$\begin{array}{lll}3.2 & 1.5-6.9 & 0.0024 \\ 1.9 & 0.9-4.1 & 0.0919\end{array}$


more optimized thresholds might lead to a better performance by serum CgA levels as biomarker. Despite these limitations, our results suggest a potential role of serum CgA in the management of CRPC patients treated with abiraterone. Serum CgA is a simple, reproducible, and low-cost biomarker, which may be a useful outcome predictor and could offer complementary information with respect to PSA. Moreover, abiraterone is administered until progression, so it appears fundamental to predict early progression rather than the tumor response to therapy. In our experience, CgA levels more than three times the UNV predicted an early radiological PD in eight of 11 cases (73\%).

In previous studies, $\mathrm{CgA}$ values were not substantially affected by either endocrine therapy or chemotherapy. The administration of a somatostatin analog in CRPC patients was able to reduce plasma $\mathrm{CgA}$ values consistently in a few cases, but neither baseline CgA nor octreoscan could identify tumor responders (Kalkner et al. 2006). PI3K/AKT/mTOR signaling pathway contributes to transition to androgen-independent disease and neuroendocrine differentiation (Carver et al. 2011, Burgio et al. 2012, Conteduca et al. 2014). Thus, targeting of PI3K/AKT/mTOR may represent a promising therapy for CRPC with neuroendocrine differentiation. PI3K and dual $\mathrm{PI} 3 \mathrm{~K} / \mathrm{mTOR}$ inhibitors are currently investigated in combination with abiraterone in metastatic CRPC, and the effect on the neuroendocrine component will be crucial for the success of these clinical trials (Conteduca et al. 2014).

In conclusion, elevated plasma $\mathrm{CgA}$ levels are frequently observed in CRPC patients after docetaxel. A plasma CgA level more than three times the UNV predicted PFS and showed a trend vs OS prediction, independently from PSA decline, in CRPC patients treated with abiraterone. The integrated use of PSA response and baseline $\mathrm{CgA}$ levels could potentially lead to a significant improvement in outcome prediction of these patients. Further larger studies should investigate serum CgA levels as a potential biomarker for outcome prediction in CRPC treated with abiraterone.

\section{Declaration of interest}

The authors declare that there is no conflict of interest that could be perceived as prejudicing the impartiality of the research reported.

\section{Funding}

This research did not receive any specific grant from any funding agency in the public, commercial, or not-for-profit sector.

\section{References}

Angelsen A, Syversen U, Haugen OA, Stridsberg M, Mjølnerød OK \& Waldum HL 1997 Neuroendocrine differentiation in carcinomas of the prostate: do neuroendocrine serum markers reflect immunohistochemical findings? Prostate 30 1-6. (doi:10.1002/(SICI) 1097-0045(19970101)30:1 < 1::AID-PROS1 > 3.0.CO;2-T)

Attard G, Reid AH, A'Hern R, Parker C, Oommen NB, Folkerd E, Messiou C, Molife LR, Maier G, Thompson E et al. 2009 Selective inhibition of CYP17 with abiraterone acetate is highly active in the treatment of castration-resistant prostate cancer. Journal of Clinical Oncology 27 3742-3748. (doi:10.1200/JCO.2008.20.0642)

Berruti A, Dogliotti L, Mosca A, Bellina M, Mari M, Torta M, Tarabuzzi R, Bollito E, Fontana D \& Angeli A 2000 Circulating neuroendocrine markers in patients with prostate carcinoma. Cancer 88 2590-2597. (doi:10.1002/1097-0142(20000601)88:11<2590::AID-CNCR23>3.0. CO;2-D)

Berruti A, Mosca A, Tucci M, Terrone C, Torta M, Tarabuzzi R, Russo L, Cracco C, Bollito E, Scarpa RM et al. 2005 Independent prognosticrole of circulating chromogranin A in prostate cancer patients with hormone-refractory disease. Endocrine-Related Cancer 12 109-117. (doi:10.1677/erc.1.00876)

de Bono JS, Oudard S, Ozguroglu M, Hansen S, Machiels JP, Kocak I, Gravis G, Bodrogi I, Mackenzie MJ, Shen L et al. 2010 Prednisone plus cabazitaxel or mitoxantrone for metastatic castration-resistant prostate cancer progressing after docetaxel treatment: a randomised open-label trial. Lancet 376 1147-1154. (doi:10.1016/S0140-6736(10)61389-X)

de Bono JS, Logothetis CJ, Molina A, Fizazi K, North S, Chu L, Chi KN, Jones RJ, Goodman OB Jr, Saad F et al. 2011 Abiraterone and increased survival in metastatic prostate cancer. New England Journal of Medicine 364 1995-2005. (doi:10.1056/NEJMoa1014618)

Burgio SL, Fabbri F, Seymour IJ, Zoli W, Amadori D \& De Giorgi U 2012 Perspectives on mTOR inhibitors for castration-refractory prostate cancer. Current Cancer Drug Targets 12 940-949. (doi:10.2174/ 156800912803251234)

Burgio SL, Conteduca V, Ruttnas B, Carrozza F, Campedelli E, Bianchi E, Fabbri P, Montanari M, Carretta E, Menna C et al. 2014 PSA flare with abiraterone in patients with metastatic castration-refractory prostate cancer. Clinical Genitourinary Cancer [in press].

Carver BS, Chapinski C, Wongvipat J, Hieronymus H, Chen Y, Chandarlapaty S, Arora VK, Le C, Koutcher J, Scher H et al. 2011 Reciprocal feedback regulation of PI3K and androgen receptor signaling in PTEN-deficient prostate cancer. Cancer Cell 19 575-586. (doi:10.1016/j.ccr.2011.04.008)

Conteduca V, Aieta M, Amadori D \& De Giorgi U 2014 Neuroendocrine differentiation in prostate cancer: current and emerging therapy strategies. Critical Reviews in Oncology/Hematology [in press].

Deftos LJ, Nakada S, Burton DW, di Sant'Agnese PA, Cockett AT \& Abrahamsson PA 1996 Immunoassay and immunohistology studies of chromogranin A as a neuroendocrine marker in patients with carcinoma of the prostate. Urology 48 58-62. (doi:10.1016/S00904295(96)00089-1)

Fagerland MW \& Hosmer DW 2013 A goodness-of-fit test for the proportional odds regression model. Statistics in Medicine 32 2235-2249. (doi:10.1002/sim.5645)

Fagerland MW, Hosmer DW \& Bofin AM 2008 Multinomial goodness-of-fit tests for logistic regression models. Statistics in Medicine 27 4238-4253. (doi:10.1002/sim.3202)

Fizazi K, Scher HI, Molina A, Logothetis CJ, Chi KN, Jones RJ, Staffurth JN, North S, Vogelzang NJ, Saad F et al. 2012 Abiraterone acetate for treatment of metastatic castration-resistant prostate cancer: final overall survival analysis of the COU-AA-301 randomised, double-blind, placebo-controlled phase 3 study. Lancet Oncology 13 983-992. (doi:10.1016/S1470-2045(12)70379-0)

Isshiki S, Akakura K, Komiya A, Suzuki H, Kamiya N \& Ito H 2002 Chromogranin A concentration as a serum marker to predict prognosis 
after endocrine therapy for prostate cancer. Journal of Urology 167 512-515. (doi:10.1016/S0022-5347(01)69075-X)

Kalkner KM, Acosta S, Thorsson O, Frederiksen H, Nilsson A, Gustavsson B, Elingsbo M, Stridsberg M \& Abrahamsson PA 2006 Octreotide scintigraphy and chromogranin A do not predict clinical response in patients with octreotide acetate-treated hormone-refractory prostate cancer. Prostate Cancer and Prostatic Diseases 9 92-98. (doi:10.1038/ sj.pcan.4500843)

Kimura N, Hoshi S, Takahahi M, Takeha S, Shizawa S \& Nagura H 1997 Plasma chromogranin A in prostatic carcinoma and neuroendocrine tumors. Journal of Urology 157 565-568. (doi:10.1016/S00225347(01)65203-0)

Matei DV, Renne G, Pimentel M, Sandri MT, Zorzino L, Botteri E, De Cicco C, Musi G, Brescia A, Mazzoleni F et al. 2012 Neuroendocrine differentiation in castration-resistant prostate cancer: a systematic diagnostic attempt. Clinical Genitourinary Cancer 10 164-173. (doi:10.1016/j.clgc. 2011.12.004)

Petrylak DP, Tangen CM, Hussain MH, Lara PN Jr, Jones JA, Taplin ME, Burch PA, Berry D, Moinpour C, Kohli M et al. 2004 Docetaxel and estramustine compared with mitoxantrone and prednisone for advanced refractory prostate cancer. New England Journal of Medicine 351 1513-1520. (doi:10.1056/NEJMoa041318)

Ryan CJ, Smith MR, de Bono JS, Molina A, Logothetis CJ, de Souza P, Fizazi K, Mainwaring P, Piulats JM, Ng S et al. 2013 Abiraterone in metastatic prostate cancer without previous chemotherapy. New England Journal of Medicine 368 138-148. (doi:10.1056/NEJMoa1209096)

Scher HI, Halabi S, Tannock I, Morris M, Sternberg CN, Carducci MA, Eisenberger MA, Higano C, Bubley GJ, Dreicer R et al. 2008 Design and end points of clinical trials for patients with progressive prostate cancer and castrate levels of testosterone: recommendations of the Prostate Cancer Clinical Trials Working Group. Journal of Clinical Oncology 26 1148-1159. (doi:10.1200/JCO.2007.12.4487)

Sciarra A, Di Silverio F, Autran AM, Salciccia S, Gentilucci A, Alfarone A \& Gentile V 2009 Distribution of high chromogranin A serum levels in patients with nonmetastatic and metastatic prostate adenocarcinoma. Urologia Internationalis 82 147-151. (doi:10.1159/000200789)

Siegel R, Naishadham D \& Jemal A 2013 Cancer statistics, 2013. CA: A Cancer Journal for Clinicians 63 11-30. (doi:10.3322/caac.21166)

Tannock IF, de Wit R, Berry WR, Horti J, Pluzanska A, Chi KN, Oudard S, Théodore C, James ND, Turesson I et al. 2004 Docetaxel plus prednisone or mitoxantrone plus prednisone for advanced prostate cancer. New England Journal of Medicine 351 1502-1512. (doi:10.1056/ NEJMoa040720)

Taplin ME, George DJ, Halabi S, Sanford B, Febbo PG, Hennessy KT, Mihos CG, Vogelzang NJ, Small EJ \& Kantoff PW 2005 Prognostic significance of plasma chromogranin A levels in patients with hormone-refractory prostate cancer treated in Cancer and Leukemia Group B 9480 study. Urology 66 386-391. (doi:10.1016/j.urology. 2005.03.040)

Received in final form 2 April 2014

Accepted 9 April 2014

Made available online as an Accepted Preprint 16 April 2014
(C) 2014 Society for Endocrinology Printed in Great Britain
Published by Bioscientifica Ltd. 